\title{
Regiões pluviometricamente homogêneas no Brasil
}

\author{
Thadeu Keller Filho ${ }^{(1)}$, Eduardo Delgado Assad ${ }^{(2)}$ e Paulo Roberto Schubnell de Rezende Lima( ${ }^{(3)}$
}

\begin{abstract}
(1)Pontifícia Universidade Católica do Rio de Janeiro, Rua Marquês de São Vicente, no 225, Sala F-210, CEP 22453-900 Rio de Janeiro, RJ. E-mail: thadeu@econ.puc-rio.br (2)Embrapa Informática Agropecuária, Av. André Tosello, 209, Barão Geraldo, Caixa Postal 6041, CEP 13083-970 Campinas, SP. E-mail: assad@cnptia.embrapa.br (3)Estocástica-Consultoria e Serviços Técnicos em Estatística Ltda, SQS 314, Bloco D, Apto. 502, CEP 70383-040 Brasília, DF. E-mail: prsrlima@yahoo.com.br
\end{abstract}

Resumo - O objetivo deste trabalho foi identificar, no Brasil, regiões homogêneas quanto à distribuição de probabilidades de chuva e assim contribuir para estudos de riscos climáticos na agricultura. As regiões foram delimitadas mediante aplicação da análise de agrupamento hierárquica, com variáveis classificatórias definidas pela proporção de pêntadas secas e por medidas de posição, escala e forma das distribuições de freqüências da quantidade de chuva. A análise de agrupamento permitiu identificar 25 zonas pluviometricamente homogêneas em todo o território brasileiro.

Termos para indexação: análise de agrupamento, zonas pluviometricamente homogêneas, riscos climáticos.

\section{Rainfall homogeneous areas in Brazil}

\begin{abstract}
The objective of this work was to identify homogeneous areas in Brazil according to the similarity of their rainfall probability distribution, in order to contribute to the studies of climatic risks in agriculture. These areas were delimited using the hierarchical cluster analysis, with discriminating variables defined by the proportion of dry pentads and by measures of location, scale and shape of the pluviometric frequency distributions. Cluster analysis was able to identify 25 rainfall homogeneous areas in the whole Brazilian territory.
\end{abstract}

Index terms: cluster analysis, rainfall homogeneous zones, climatic risks.

\section{Introdução}

O alto desempenho da agricultura brasileira e o crescimento expressivo de sua produtividade a partir da década de 90 é resultado de uma verdadeira revolução tecnológica ocorrida nos principais segmentos do setor agrícola.

Para reduzir o risco climático na agricultura e diminuir as perdas de safra, o Ministério da Agricultura, Pecuária e Abastecimento (MAPA) instituiu, em outubro de 1995, o Projeto de Redução de Riscos Climáticos na Agricultura, como fase inicial de implantação do Programa de Zoneamento Agrícola do Brasil.

Mediante aplicação de métodos agroclimatológicos, o Programa de Zoneamento Agrícola do Brasil passou a orientar os produtores quanto aos tipos de cultura a serem plantadas em cada região e quanto às épocas de plantio mais favoráveis (Assad et al., 2001).

A quantificação dos riscos decorrentes de fatores climáticos adversos foi objeto de uma abordagem probabilística para determinar as chances de sucesso das diversas culturas em cada região e época de plan- tio, principalmente no que se refere à influência da precipitação pluvial (Keller, 1998; Schubnell, 1998).

Na agricultura brasileira, o mais importante fator de risco climático é a precipitação pluvial, pois a seca e a chuva excessiva respondem pela maioria dos sinistros agrícolas (Göpfert et al., 1993).

A aplicação dessa abordagem probabilística exige o agrupamento das observações pluviais segundo um critério de similaridade do comportamento probabilístico da precipitação pluvial, em sua evolução ao longo de um período anual.

O objetivo deste trabalho foi identificar, no Brasil, regiões homogêneas quanto à distribuição de probabilidades de chuva e assim contribuir para os estudos de riscos climáticos na agricultura.

\section{Material e Métodos}

Um dos métodos mais utilizados para se classificar objetos em categorias de similaridade é a análise de agrupamento (cluster analysis). Essa técnica considera um conjunto inicial de objetos, aos quais são associadas 
medidas de várias grandezas, denominadas variáveis classificatórias, utilizadas para se obter grupos de objetos assemelhados em relação aos valores assumidos por essas variáveis (Everitt, 1993).

A análise de agrupamento, muitas vezes associada à análise de componentes principais, tem sido utilizada na climatologia para a definição de regiões climáticas homogêneas (Munõz-Diaz \& Rodrigo, 2003; Unal et al., 2003; Uvo, 2003).

Neste trabalho, foram utilizados dados da precipitação pluvial diária cedidos pelo Departamento Nacional de Águas e Energia Elétrica (DNAEE), atual Agência Nacional de Águas (ANA), referentes a 2.341 postos pluviométricos dispersos em todo o território brasileiro (Tabela 1). Inicialmente, os dados foram avaliados quanto à atualidade, ausência de erros, completude e consistência. Para analisar a consistência dos dados e obter

Tabela 1. Relação dos postos pluviométricos utilizados e do número de anos de observação, por Região e por Unidade da Federação.

\begin{tabular}{|c|c|c|c|c|}
\hline Região & Estado & $\begin{array}{l}\text { Número } \\
\text { de postos }\end{array}$ & $\begin{array}{l}\text { Número } \\
\text { mínimo } \\
\text { de anos }\end{array}$ & $\begin{array}{l}\text { Número } \\
\text { máximo } \\
\text { de anos }\end{array}$ \\
\hline \multirow[t]{7}{*}{ Norte } & Acre & 6 & 15 & 18 \\
\hline & Amazonas & 65 & 15 & 20 \\
\hline & Amapá & 10 & 15 & 18 \\
\hline & Pará & 81 & 15 & 20 \\
\hline & Rondônia & 11 & 15 & 19 \\
\hline & Roraima & 5 & 15 & 18 \\
\hline & Tocantins & 55 & 15 & 23 \\
\hline \multirow[t]{8}{*}{ Nordeste } & Alagoas & 54 & 15 & 18 \\
\hline & Bahia & 142 & 15 & 21 \\
\hline & Ceará & 159 & 15 & 28 \\
\hline & Maranhão & 78 & 15 & 21 \\
\hline & Paraíba & 99 & 15 & 21 \\
\hline & Pernambuco & 152 & 15 & 18 \\
\hline & Piauí & 148 & 15 & 20 \\
\hline & Sergipe & 67 & 15 & 25 \\
\hline \multirow[t]{5}{*}{ Sudeste } & Espírito Santo & 98 & 15 & 18 \\
\hline & Minas Gerais & 165 & 15 & 19 \\
\hline & Rio de Janeiro & 89 & 15 & 20 \\
\hline & Rio Grande do Norte & 97 & 15 & 18 \\
\hline & São Paulo & 172 & 15 & 20 \\
\hline \multirow[t]{3}{*}{ Sul } & Paraná & 129 & 15 & 35 \\
\hline & Rio Grande do Sul & 198 & 15 & 20 \\
\hline & Santa Catarina & 128 & 15 & 20 \\
\hline Centro- & Goiás & 65 & 15 & 29 \\
\hline \multirow[t]{2}{*}{ Oeste } & Mato Grosso & 45 & 15 & 30 \\
\hline & Mato Grosso do Sul & 23 & 15 & 25 \\
\hline Total & & 2.341 & 15 & 35 \\
\hline
\end{tabular}

Fonte: DNAEE/ANA; os dados diários podem ser encontrados em www.agritempo.gov.br/cthidro. sua homogeneização, foram utilizados os métodos da Dupla Massa (Pinto et al., 2000) e do Vetor Regional (Hiez, 1977). No preenchimento das falhas, empregou-se também o método dos Vizinhos mais Próximos (Pinto et al., 2000). Os dados usados neste trabalho foram analisados sob todos esses aspectos por Lima (2003).

Desse modo, foram obtidas séries históricas consistentes, abrangendo períodos entre 15 e 35 anos para cada posto pluviométrico (Tabela 1). A seguir, foi organizado um banco de dados estruturado com o conjunto dos postos pluviométricos, georreferenciados por meio das coordenadas latitude e longitude, e com as correspondentes séries históricas das precipitações pluviais. Os dados foram agrupados em períodos consecutivos de cinco dias, ou pêntadas, e a cada um deles se associou o total da precipitação pluvial no período. Na análise, convencionou-se que, nos anos bissextos, a 12a pêntada, correspondente ao período de 25 de fevereiro a $1{ }^{\circ}$ de março, é constituída de seis dias.

O passo seguinte foi a escolha de um procedimento adequado para a formação de grupos homogêneos de observações pluviais. De modo geral, os procedimentos existentes para aplicação da análise de agrupamento desdobram-se em quatro etapas: escolha das variáveis classificatórias, especificação de uma medida de similaridade, seleção do método de agrupamento e decisão quanto ao número de grupos a serem formados.

\section{Variáveis classificatórias}

A escolha dessas variáveis reflete o julgamento do investigador sobre a relevância dos fatores climáticos para os propósitos da pesquisa. Na agrometeorologia, são mais utilizadas variáveis que correspondem à temperatura (média, máxima e mínima) e à precipitação pluvial total, geralmente referida a períodos mensais.

Neste trabalho, a escolha das variáveis classificatórias teve por finalidade a formação de grupos homogêneos de observações pluviais para os quais as distribuições de probabilidade de chuva possuam um perfil assemelhado ao longo de sua evolução no tempo.

De um ponto de vista descritivo, as distribuições de probabilidade diferem entre si por características de posição, escala e forma. Quanto à forma, as características mais importantes para diferenciar o perfil das distribuições são o seu grau de assimetria e seu grau de curtose, ou achatamento. Nas distribuições de probabilidades da precipitação pluvial referentes a determinado período, outra característica diferenciadora é a probabilidade de ocorrência de períodos de estiagem. 
Por isso, as variáveis classificatórias foram escolhidas de forma a captar as flutuações da posição, da escala e da forma das distribuições de freqüência da chuva ao longo de todas as pêntadas de um ano, bem como da proporção de pêntadas em que houve estiagem. Assim, para cada uma das 73 pêntadas do ano, foram calculados os seguintes indicadores das características que diferenciam as distribuições de chuva em cada ponto de observação pluviométrica: média aritmética (parâmetro de posição), desvio-padrão (parâmetro de escala), coeficientes de assimetria e de curtose (parâmetros de forma) e proporção de pêntadas secas.

Dessa forma, a cada ponto de observação pluviométrica fez-se corresponder um vetor de 365 parâmetros (5 parâmetros x 73 pêntadas) para caracterizar o perfil estatístico do regime de precipitação pluvial ao longo de um período anual.

\section{Medida de similaridade}

Na análise de agrupamento, é fundamental a definição de uma medida de similaridade ou de distância entre os grupos a serem constituídos. Como as variáveis classificatórias escolhidas são variáveis reais e, portanto, são mensuradas em uma escala de intervalo, é conveniente adotar uma medida de distância com propriedades métricas, tendo a escolha recaído na métrica Euclidiana, por ser essa a mais utilizada (Everitt, 1993). Como as variáveis classificatórias são mensuradas em unidades distintas, seus valores foram previamente estandardizados, de forma a terem média zero e variância unitária (Green, 1978).

\section{Método de agrupamento}

Ao longo das últimas décadas, sob o estímulo do grande progresso da tecnologia da computação, foram desenvolvidos inúmeros métodos para o agrupamento de objetos. Distinguem-se dois tipos de métodos de agrupamento: métodos não-hierárquicos, que produzem um número fixo de agrupamentos e métodos hierárquicos, que formam agrupamentos por meio de uma seqüência crescente de partições de grupos - abordagem divisiva - ou de junções sucessivas de grupos - abordagem aglomerativa.

Para agrupar observações pluviais, não é possível estabelecer a priori o número ideal de grupos a serem formados. Nesse caso, os métodos não-hierárquicos são inconvenientes, pois sua aplicação exigiria grande esforço de cálculo nas sucessivas tentativas para encontrar o número adequado de agrupamentos. Assim, ado- tou-se o método hierárquico aglomerativo, que é o mais utilizado na construção de agrupamentos (Kaufman \& Rousseau, 1990).

Várias técnicas de agrupamento hierárquico têm sido propostas, destacando-se, dentre as mais utilizadas (Everitt, 1993): ligação simples (single linkage method); ligação completa (complete linkage method); método centróide (centroid method); método da mediana (median method); método da média dos grupos (group average method) e método da variância mínima (Ward's method).

A escolha de uma dessas técnicas é, de certa forma, subjetiva. Neste trabalho, utilizamos o método da variância mínima (Ward, 1963), recomendado por Edelbrock (1979), com base em vários estudos empíricos.

Nesse método, a formação dos agrupamentos em cada estágio da hierarquia é avaliada pela soma dos quadrados dos desvios em relação ao centro de gravidade dos grupos, geralmente indicada por $\mathrm{R}^{2}$. O critério para a fusão de cada par de grupos é o de que seja obtido o menor acréscimo possível no valor de $\mathrm{R}^{2}$.

\section{Número de grupos}

Segundo Hartigan (1985), não existe um método inteiramente satisfatório para a determinação do número ideal de grupos. Com esse propósito, utilizamos o Critério Cúbico para Agrupamento, instituído por Sarle (1983). Esse critério baseia-se na construção de uma medida, indicada por CCC (Cubic Clustering Criterion) que compara os valores observados de $\mathrm{R}^{2}$ com uma aproximação de $E\left(R^{2}\right)$, ou seja, de seu valor esperado. Calculase o valor de CCC após cada etapa da construção hierárquica dos grupos. Quando o CCC é positivo, os valores observados de $\mathrm{R}^{2}$ são superiores a $\mathrm{E}\left(\mathrm{R}^{2}\right)$, indicando a provável existência de novos agrupamentos significantes. Milligan \& Cooper (1985) compararam o desempenho de um grande número de critérios para determinar o número ideal de grupos, chegando à conclusão de que o CCC é um dos que apresentaram melhores resultados.

\section{Resultados e Discussão}

Na fase preliminar do estudo, a análise de agrupamento foi utilizada para formar grandes aglomerados de observações pluviais, a fim de verificar se sua distribuição espacial é consistente com a diversificação climática existente no Brasil. Por meio do método hierárquico da variância mínima (Ward, 1963), foi possível identifi- 
car seis grandes aglomerações de observações pluviais em todo o Brasil, as quais passaram a ser denominadas áreas homogêneas, identificadas como área 1, área 2, área 3, área 4, área 5 e área 6 (Figura 1).
Esses grupos estão situados em áreas climáticas distintas, com regime de precipitação pluvial bastante diversificado. De fato, a precipitação pluvial média ao longo de um ano apresenta um grande contraste entre as

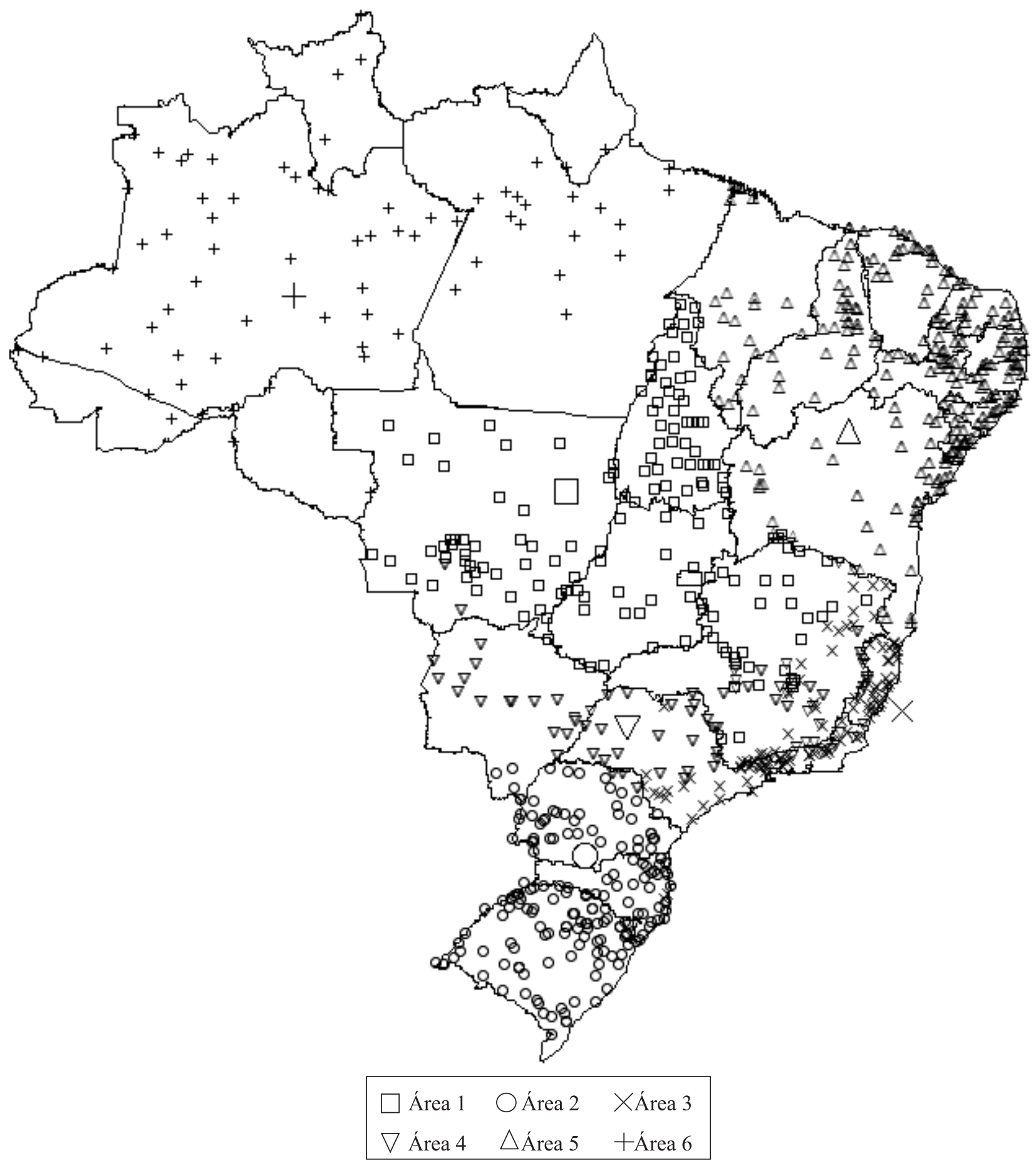

Figura 1. Distribuição espacial dos pontos de observação pluviométrica, segundo as áreas homogêneas. 
áreas homogêneas, com exceção das áreas 3 e 4 (Figura 2). Por sua vez, a proporção de pêntadas secas ao longo de um ano é muito diferente em todas as áreas homogêneas, inclusive nas áreas 3 e 4 (Figura 3).

Portanto, considerada como uma análise exploratória preliminar, essa identificação de seis áreas homogêneas produziu bons resultados, apesar da baixa densidade espacial dos postos pluviométricos existentes nos estados de Mato Grosso, Mato Grosso do Sul, e na Região Norte, exceto o Estado de Tocantins.

Considerando, entretanto, que a precipitação pluvial é influenciada por fatores físico-geográficos, como posição, extensão latitudinal e relevo, deve-se esperar que, em grandes extensões territoriais, o regime de chuva não seja muito homogêneo. Por isso, o método de Ward foi também utilizado para subdividir cada área homogênea em várias zonas homogêneas, nas quais o regime de chuva apresenta um grau de homogeneidade suficiente para os propósitos do estudo. Para determinar o número ideal de zonas homogêneas, utilizou-se o Critério Cúbico para Agrupamento (Sarle, 1983).

Assim, foram identificadas as seguintes zonas homogêneas: A, B, C e D (área 1); E, F, G, H, I e J (área 2); K, L, M e N (área 3); O, P e Q (área 4); R, S, T, U, V e X (área 5) e Y e Z (área 6). Dessa forma, o território brasileiro ficou dividido em seis áreas homogêneas, subdivididas em 25 zonas homogêneas. As Figuras 4 a 8 apresentam a distribuição espacial dos pontos de observação pluviométrica, por grandes regiões, segundo as zonas homogêneas.

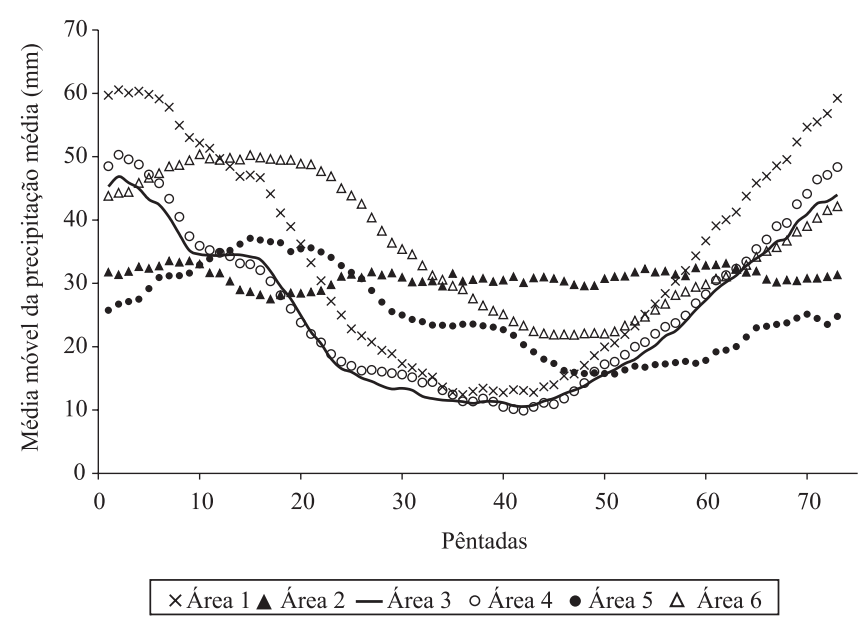

Figura 2. Médias móveis da precipitação pluvial média, por pêntada, segundo as áreas homogêneas.
A área 1, em sua quase totalidade, está inserida no ecossistema dos Cerrados brasileiros, o qual abrange uma área aproximada de 204 milhões de hectares. Em virtude de seu posicionamento latitudinal, a região caracteriza-se pela transição entre os climas quentes de latitudes baixas e os climas mesotérmicos do tipo temperado, de latitudes médias (Nimer, 1989). Nos estudos feitos por Rao \& Hada (1990) e adaptados por Silva Dias \& Marengo (1999), a região é considerada praticamente homogênea quanto à duração e posicionamento dos períodos secos e chuvosos. Entretanto, Castro et al. (1994) mostram que essa região apresenta um certo grau de heterogeneidade, decorrente da diversidade de duração dos períodos secos e chuvosos.

As quatro zonas homogêneas identificadas apresentam diferenças de até dois meses na duração dos períodos secos e chuvosos. Essa heterogeneidade é determinada pelos sistemas atmosféricos que atuam na área 1. A Região do Cerrado encontra-se sob a influência dos anticiclones do Atlântico Sul e migratório Polar, além das depressões do Chaco e Amazônica. O anticiclone do Atlântico Sul, também conhecido como ZCAS (zona de convergência do Atlântico Sul), é um dos principais fenômenos que determinam o regime de chuvas em toda a região (Vianello \& Alves, 1991; Quadro, 1994; Oliveira et al., 2001).

De modo geral, a zona A abrange o norte de Tocantins e parte de Mato Grosso, com uma precipitação pluvial relativamente elevada (maior que $1.500 \mathrm{~mm}$ ); a zona B abrange o sul do Estado de Tocantins e quase todo o

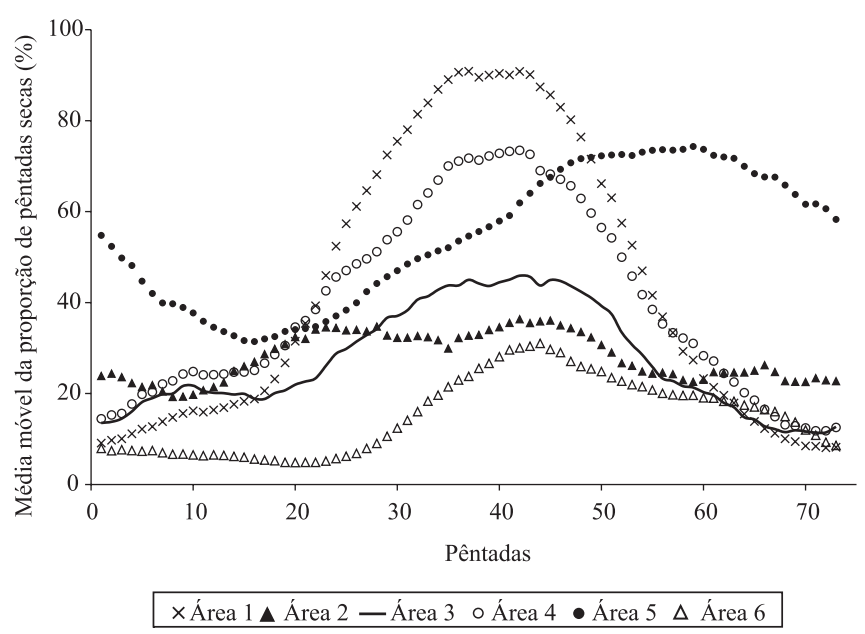

Figura 3. Médias móveis das proporções de pêntadas secas, por pêntada, segundo as áreas homogêneas. 
Estado de Goiás, com índices médios de precipitação pluvial (de 1.000 a $1.500 \mathrm{~mm}$ ); a zona C está situada ao norte de Minas Gerais, constituindo uma zona de transição para o clima nordestino (precipitação até $1.100 \mathrm{~mm}$ ); a zona D, situada a noroeste de Minas Gerais, é uma zona de transição entre o clima Tropical e o Litorâneo Úmido (precipitação entre 1.100 e 1.500 mm).

A área 2 está quase toda situada na Região Sul, onde predomina o clima Subtropical Úmido. Nessa região atuam os vórtices ciclônicos de alto nível de origem subtropical que provocam chuvas e ventos fortes (Silva Dias \& Grammelsbacher, 1991), os sistemas frontais - Pacífico, Argentina, Sul-Sudeste e Nordeste - e a zona de convergência do Atlântico Sul. A complexa ação desses sistemas atmosféricos pode explicar a identificação de seis zonas homogêneas, as quais, devido a condições de relevo, apresentam sistemas de exploração agrícola diferenciados, tais como: zonas E e F, fruticultura temperada; zonas G e I, produção de grãos, culturas de inverno e verão; zona $\mathrm{H}$, pequena produção diversificada; e zona J, terras baixas, produção de arroz irrigado e atividade pecuária.

As zonas E, F, G e H possuem regimes de precipitação pluvial relativamente homogêneos; a zona I abrange o norte do Paraná e o sul de Mato Grosso do Sul, sendo uma zona de transição para o regime de precipitação pluvial prevalecente em São Paulo e no Mato Grosso do Sul.
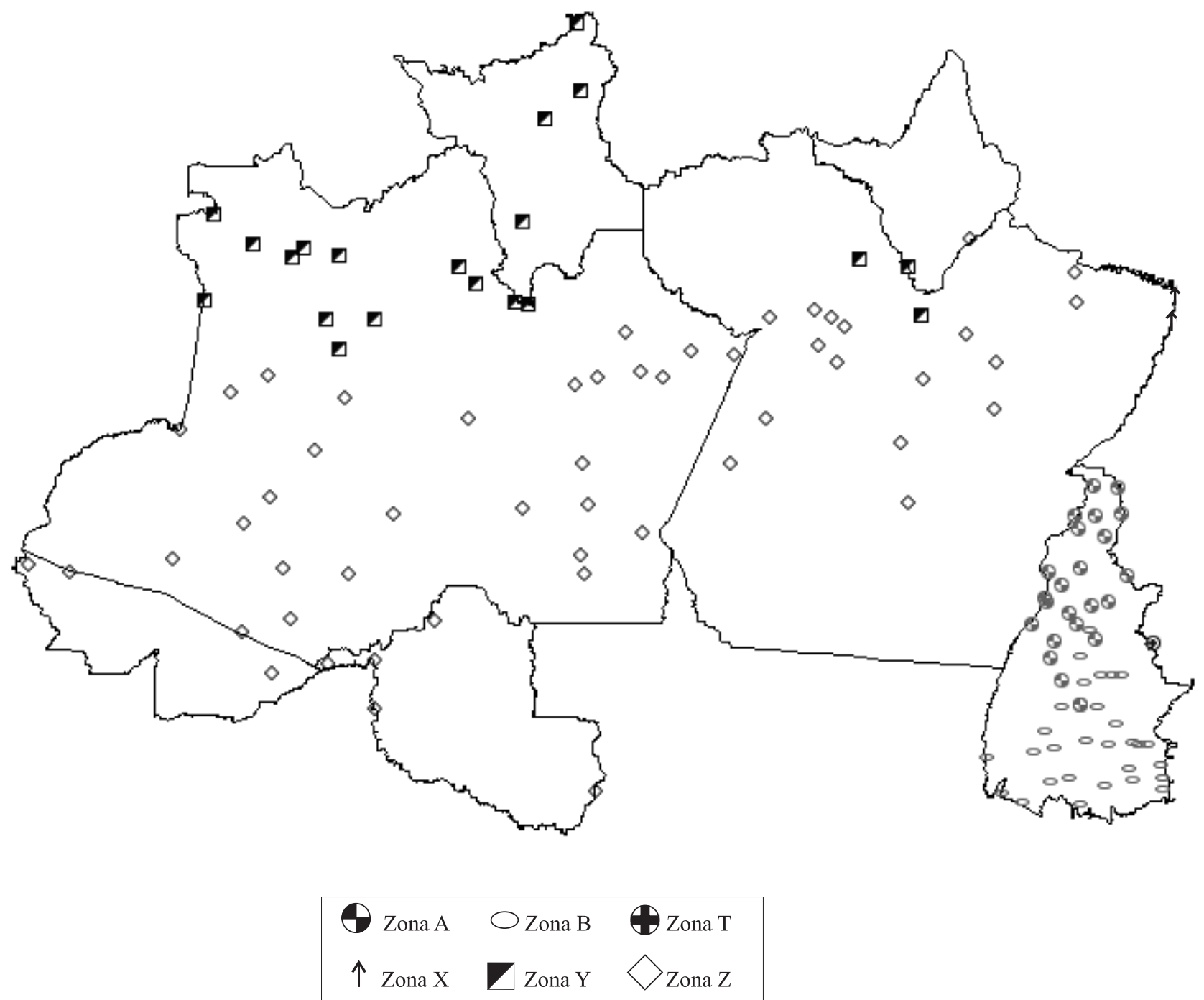

Figura 4. Distribuição espacial dos pontos de observação pluviométrica na Região Norte, segundo as zonas homogêneas. 
A região da área 3 também é caracterizada pela transição entre climas quentes das latitudes baixas e climas mesotérmicos das latitudes médias (Nimer, 1989). Em geral, os totais pluviais anuais variam de $1.500 \mathrm{~mm}$ a $2.000 \mathrm{~mm}$. No litoral, principalmente no norte de São Paulo, a precipitação pluvial é elevada, podendo atingir níveis de $3.500 \mathrm{~mm}$ a $4.000 \mathrm{~mm}$ anuais, sem estação seca definida.

A variação do regime pluvial na área 3 permitiu identificar quatro zonas homogêneas: a zona K, que é chuvosa, estende-se do oeste de Minas Gerais até a fronteira de São Paulo; a zona L, chuvosa, estendendo-se
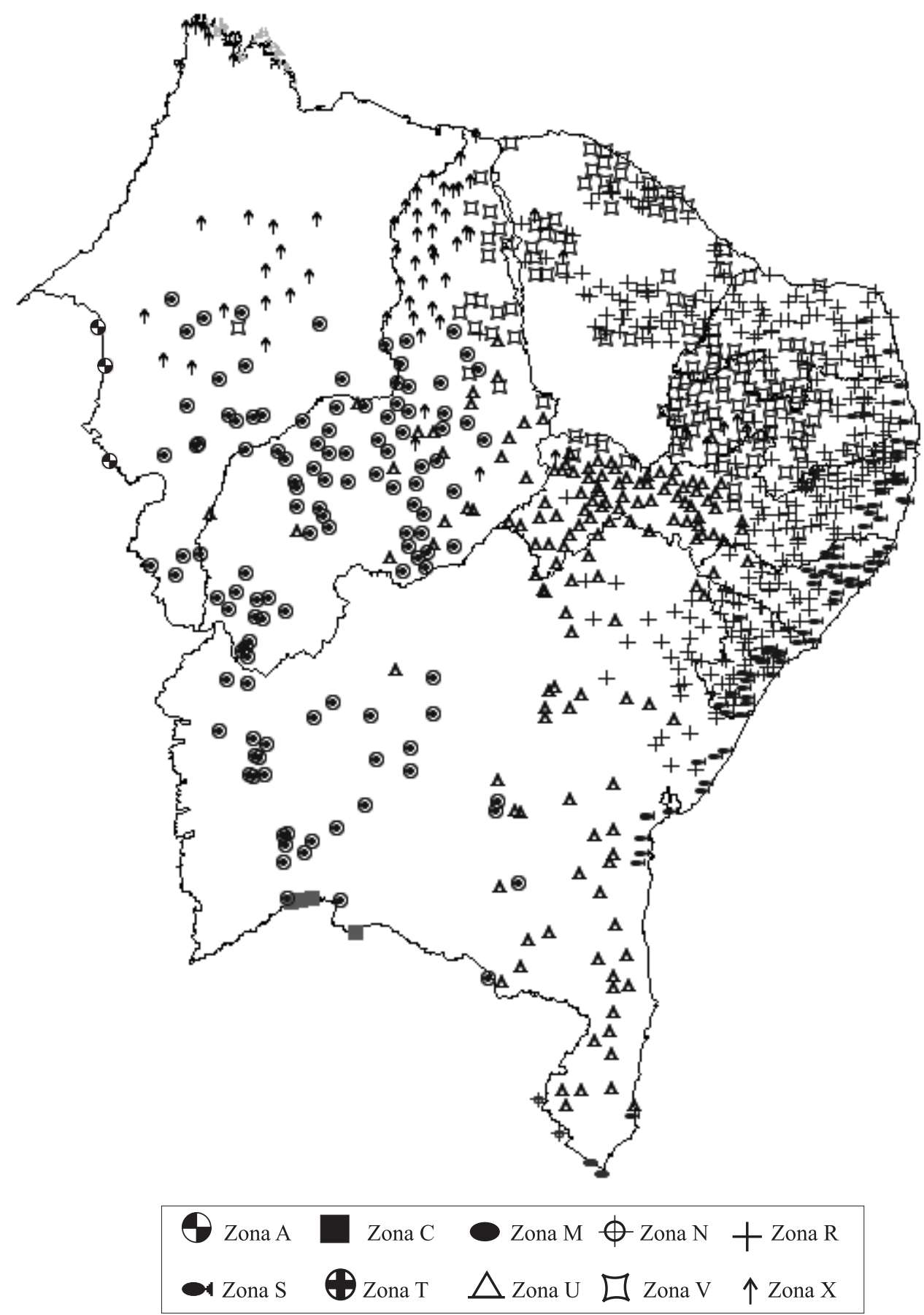

Figura 5. Distribuição espacial pontos de observação pluviométrica na Região Nordeste, segundo as zonas homogêneas. 
do oeste de Minas Gerais até o Rio de Janeiro; e as zonas N e M, que acompanham o litoral e a Serra do Mar, onde predomina o clima Litorâneo Úmido.

A área 4 abrange o Estado de São Paulo, sul e sudeste do Estado de Minas Gerais e a parte central do Estado de Mato Grosso do Sul. Os principais sistemas atmosféricos que geram as chuvas nessa área são correntes perturbadas do sul, sob forma de passagens frontais e ramos aquecidos que detém $67 \%$ da gênese das chuvas (Tarifa, 1975), zonas de convergência do Atlântico Sul e vórtices ciclônicos. O conjunto desses sistemas é uma possível explicação para a identificação de três zonas homogêneas nessa área: zona $\mathrm{O}$, que é uma zona de transição, abrangendo o oeste de Mato Grosso do Sul e parte do leste de Minas Gerais; zona P, abrangendo parte do oeste de Minas Gerais, sendo uma zona de transição entre as zonas $\mathrm{O}$ e Q; zona Q, cobrindo grande parte de São Paulo e parte de Mato Grosso do Sul, abrangendo áreas não contíguas, de regime pluvial assemelhado e com pluviosidade média.

A área 5 abrange quase toda a Região Nordeste, onde prevalecem os climas Tropical, Tropical Semi-Árido e Litorâneo Úmido e apresenta grande complexidade na distribuição e intensidade de chuvas. A diversidade do regime de precipitação pluvial nessa região pode ser explicada pela forte influência da Zona de Convergên-

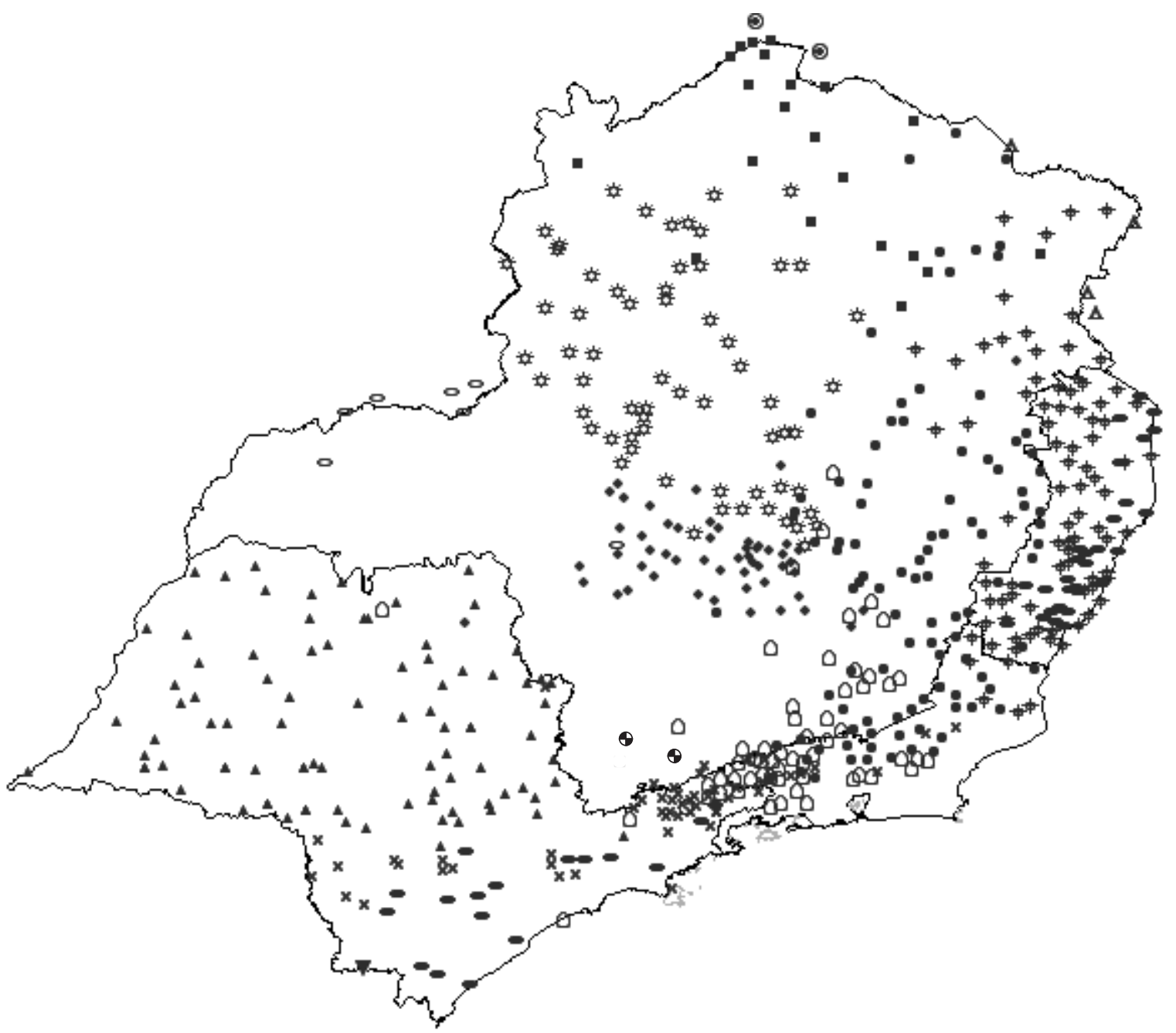

Zona C

Zona $\mathrm{M} \oplus$ Zona $\mathrm{N}$

$\triangle$ Zona $\mathrm{O}$

Zona $\mathrm{P}$

Zona $\mathrm{Q}$

$\theta$ Zona $\mathrm{T} \triangle$ Zona $\mathrm{U}$

Figura 6. Distribuição espacial dos pontos de observação pluviométrica na Região Sudeste, segundo as zonas homogêneas. 
cia Intertropical, onde ocorre a interação de características atmosféricas e oceânicas, tais como: a zona de confluência dos ventos alísios; a zona do cavado equatorial; a zona de máxima temperatura da superfície do mar; a zona de máxima convergência de massa; e a zona de banda de máxima cobertura de nuvens convectivas (Silva Dias \& Marengo, 1999).
O estudo de Rao \& Hada (1990) indicou, no nordeste brasileiro, a existência de quatro regiões com precipitação pluvial de características bem distintas. Neste trabalho, a análise de agrupamento identificou seis zonas pluviometricamente homogêneas: zona S, que é influenciada pelo clima Litorâneo Úmido; zona T, que abrange parte do sertão nordestino, no qual predomina o clima
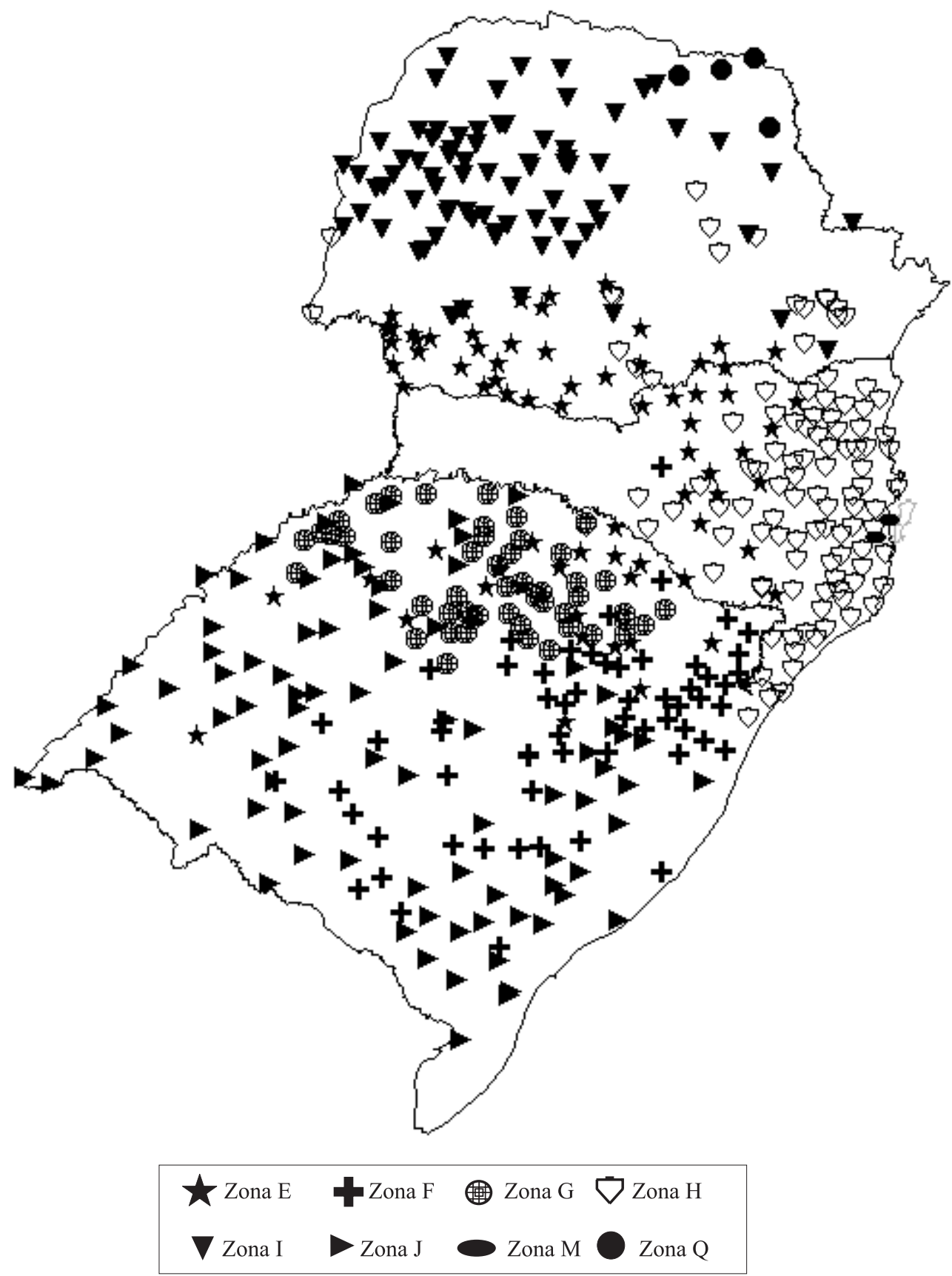

Figura 7. Distribuição espacial dos pontos de observação pluviométrica na Região Sul, segundo as zonas homogêneas. 
Tropical Semi-Árido; zonas U, V e R , que são zonas de transição entre o clima Tropical Semi-Árido e o clima Litorâneo Úmido; zona X, que abrange principalmente o Maranhão, onde predomina o clima Tropical. Nota-se a presença de uma região fronteiriça com a zona A da área 1, situada entre Tocantins e Maranhão.

A área 6 compreende a Região Norte, com precipitação pluvial elevada, influenciada por linhas de instabili- dade, onde as regiões central, sudoeste e leste, apresentam estação seca bem definida. Essa região apresenta importante heterogeneidade espacial e sazonal da pluviosidade e possui o maior total pluvial anual. Segundo Nobre (1988) e Nobre et al. (1991), os principais fatores que influenciam o regime de chuvas nessa região estão associados à condensação do ar úmido trazido pelos ventos de leste da Zona de Convergência Intertropical,

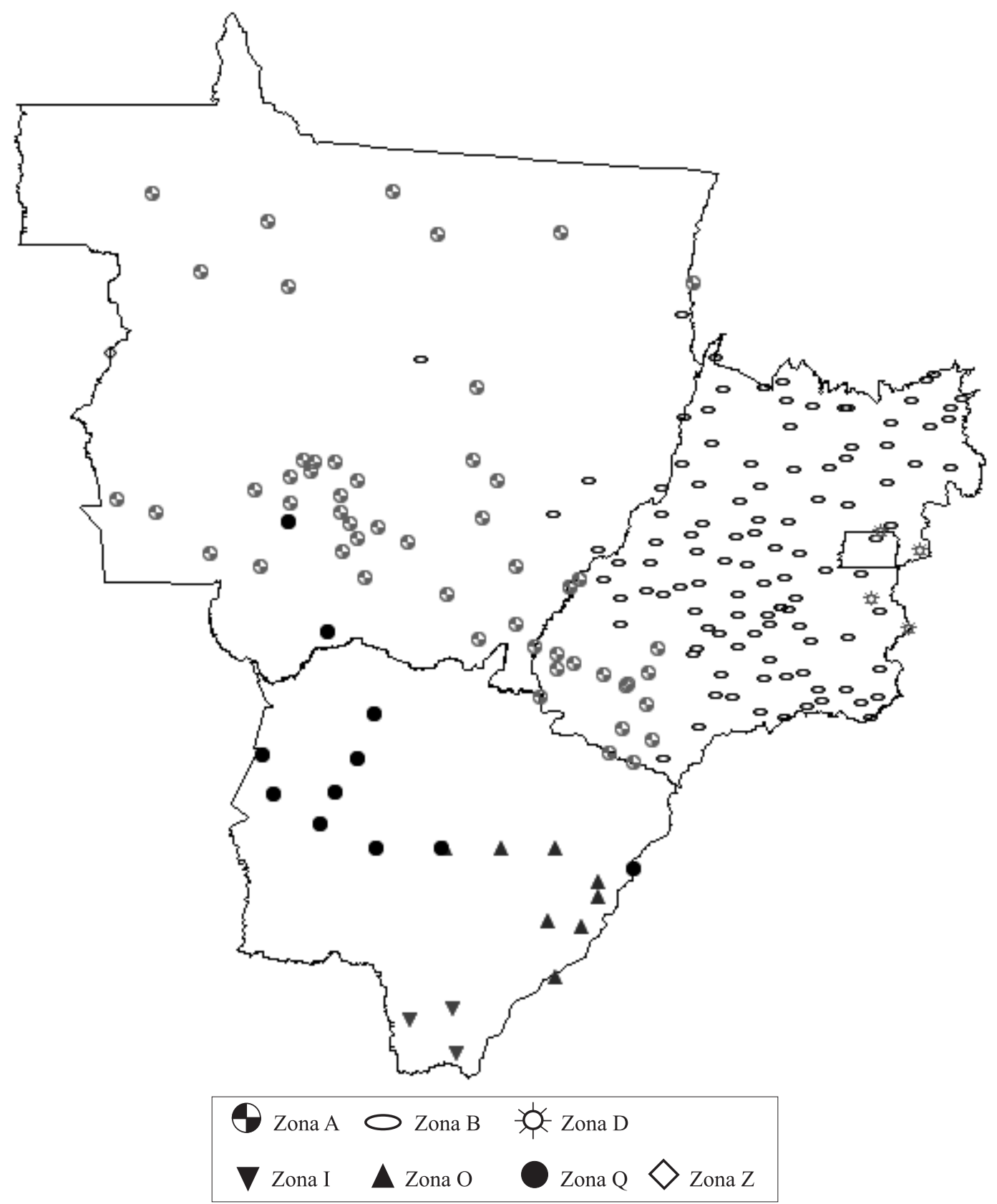

Figura 8. Distribuição espacial dos pontos de observação pluviométrica na Região Centro-Oeste, segundo as zonas homogêneas. 
além das respostas à flutuação dinâmica do centro de convecção, quase permanente na Amazônia, conforme explicado por Hastenrath (1993).

Silva Dias \& Marengo (1999) indicam a existência de quatro núcleos de precipitação abundante nessa área. Neste trabalho, pela análise de agrupamento, foram identificadas as zonas homogêneas Y e Z, com características compatíveis com suas indicações.

A zona Y é bastante chuvosa, com predomínio do clima Equatorial Úmido, enquanto a zona $\mathrm{Z}$ é menos chuvosa, constituindo um corredor na direção noroestesudeste, de Roraima ao leste do Pará.

A identificação de zonas pluviometricamente homogêneas é fundamental para o Zoneamento Agrícola do Brasil, servindo de base para a definição do calendário agrícola. O conhecimento detalhado dos padrões pluviais de regiões homogêneas é um auxílio inestimável para a escolha das culturas de menor risco e para o estabelecimento das datas de plantio mais favoráveis.

Assim, por exemplo, a cultura de milho na área 5 apresenta menor risco na zona $\mathrm{T}$, que abrange praticamente todo o Agreste nordestino, do que nas Zonas $\mathrm{U}$ e $\mathrm{V}$, que abrangem a região da Serra do Araripe, em Pernambuco, pois os índices de precipitação pluvial nessas zonas são menores que os da zona $\mathrm{T}$.

Outro exemplo é o das regiões do sul do Maranhão, sul do Piauí, oeste e sudoeste da Bahia, abrangidas pela zona T. Essas regiões são limítrofes entre o Cerrado e o Semi-Árido e apresentam um comportamento pluvial muito próximo ao das zonas que compõem a área 1, o que vem causando um avanço da fronteira agrícola do Centro-Oeste em direção ao Nordeste, tendo como limite a região do Semi-Árido, de maior risco agrícola.

Análises dessa natureza mostram que é pequeno o risco do cultivo do milho safrinha no sul de Goiás e sul do Mato Grosso, devido à maior duração do período chuvoso observado na zona $\mathrm{A}$ da área 1 , que abrange essas regiões. Entretanto, no Vale do Paranapanema, em São Paulo, abrangido pela zona $\mathrm{N}$ da área 3, o risco dessa cultura é muito alto.

A ocorrência de períodos chuvosos pode também explicar a variação da duração dos ciclos da cultura do trigo no Paraná, onde o plantio começa em março na zona F da área 2, com cultivares de ciclo médio e precoce, e termina em junho na zona $\mathrm{G}$ da área 2, somente com cultivar de ciclo precoce. Esse calendário de plantio visa principalmente evitar a colheita em períodos com forte risco de ocorrência de chuva e a conseqüente redução da qualidade do grão.

\section{Conclusões}

1. A análise de agrupamento hierárquica é um instrumento adequado na identificação de zonas homogêneas quanto ao regime de chuva.

2. A utilização de variáveis classificatórias definidas por meio da proporção de pêntadas secas e de medidas de posição, escala e forma da distribuição da precipitação pluvial permite, de forma eficiente, formar grupos de observações pluviais similares quanto ao regime de chuva.

3. A análise hierárquica de agrupamento permitiu identificar 25 zonas pluviometricamente homogêneas, localizadas em seis áreas representativas da diversidade climática do território brasileiro.

\section{Referências}

ASSAD, E.D.; MACEDO, M.A. de; CÂMARA, G.; OLIVEIRA, J.C. de; BARBOSA, A.M. Avaliação de métodos para espacialização de índices de necessidade hídrica das culturas e sua aplicação em zoneamento agrícola. Revista Brasileira de Agrometeorologia, v.9, p.581-587, 2001.

CASTRO, L.H.R.; MOREIRA, A.M.; ASSAD, E.D. Definição e regionalização dos padrões pluviométricos dos cerrados brasileiros. In: ASSAD, E.D. Chuvas nos cerrados: análise e espacialização. Brasília, Embrapa-CPAC/Embrapa-SPI, 1994. 423p.

EDELBROCK, C. Comparing the accuracy of hierarchical clustering algorithms: the problem of classifying everybody. Multivariate Behavior Research, v.14, p.367-384, 1979.

EVERITT, B.S. Cluster analysis. $3^{\text {rd }}$ ed. London: Heinemann Educational Books, 1993. 122p.

GÖPFERT, H.; ROSSETTI, L.A.; SOUZA, J. Eventos generalizados e seguridade agrícola. Brasília: IPEA, 1993. 65p.

GREEN, P.E. Analyzing multivariate data. Hinsdale, Illinois: The Dryden Press, 1978. 519p.

HARTIGAN, J.A. Statistical theory in clustering. Journal of Classification, v.2, p.63-76, 1985.

HASTENRATH, S.; GEISCHAR, L. Further work of Northeast Brazil rainfall anomalies. Journal of Climate, v.6, p.743-758, 1993.

HIEZ, G. L’homogénéité des données pluviométriques. Cahiers Orstom, Série Hydrologie, v.14, p.129-172, 1977.

KAUFMAN, L.; ROUSSEAU, W. Finding groups in data: an introduction to cluster analysis. New York: John Wiley \& Son, 1990.

KELLER,T. Redução do risco climático na agricultura: uma abordagem probabilística: 1-Metodologia, principais aspectos. In: SIMPÓSIO INTERNACIONAL DE SECURIDADE E ZONEAMENTO AGRÍCOLA DO MERCOSUL, 1., 1998, Brasília. Anais. Brasília, Ministério da Agricultura e Abastecimento, 1998. p.40-47. 
LIMA, J.G.S. Gerenciamento de dados climatológicos heterogêneos em agricultura. 2003. 103p. Dissertação (Mestrado) - Universidade Estadual de Campinas, Campinas.

MILLIGAN, G.W.; COOPER, M.C. An examination of procedures for determining the number of clusters in a dataset. Psychometrika, v.50, p.159-179, 1985.

MUÑOZ-DIAZ, D.; RODRIGO, F.S. The North Atlantic oscillation and winter rainfall over the Siberian Peninsula as captured by cluster analysis. Geophysical Research Abstracts, v.5, p.865-885, 2003.

NIMER, E. Climatologia do Brasil. 2.ed. Rio de Janeiro: Fundação IBGE, 1989. 421p.

NOBRE, C.A. Ainda sobre a zona de convergência do Atlântico Sul: a importância do Oceano Atlântico. Climanálise, v.3, p.30-33, 1988.

NOBRE, C.A.; SELLERS, P.; SHUKLA, J. Amazonian deforestation and regional climate change. Journal of Climate, v.4, p.957988, 1991.

OLIVEIRA, L.L.; VIANELLO, R.L.; FERREIRA, N.J. Meteorologia fundamental. Erechim, RS: Edifapes, 2001. 423p.

PINTO, N.L. de S.; HOLTZ, A.C.T.; MARTINS, J.A.; GOMIDE, F.L.S. Hidrologia básica. São Paulo: Edgard Blücher, 2000. 78p.

QUADRO, M.F.L. Estudo de episódios de Zonas de Convergência do Atlântico Sul (ZCAS) sobre a América do Sul.1994. 97p. Tese (Mestrado) - Instituto Nacional de Pesquisas Espaciais, São José dos Campos.

RAO, V.B.; HADA, K. Characteristics of rainfall over Brazil: annual variations and connections with the southern oscillations. Theoretical and Applied Climatology, v.2, p.81-91, 1990.
SARLE, W.S. Cubic clustering criterion. Cary, NC: SAS Institute, 1983. 39p. (SAS Technical Report A-108).

SCHUBNELL, P.R. Redução do risco climático na agricultura: uma abordagem probabilística. 2- Resultados obtidos. In: SIMPÓSIO INTERNACIONAL DE SECURIDADE E ZONEAMENTO AGRÍCOLA DO MERCUSUL, 1., 1998, Brasília. Anais. Brasília, Ministério da Agricultura e do Abastecimento, 1998. p.48-57.

SILVA DIAS, M.A.; GRAMMELSBACHER, E. A possível ocorrência do tornado em São Paulo no dia 26 de abril de 1991: um estudo de caso. Revista Brasileira de Meteorologia, v.6, p.513522, 1991.

SILVA DIAS, P.L.; MARENGO, J.A. Águas atmosféricas. In: REBOUÇAS, A.C.R.; BRAGA, B.; TUNDIZI, J.G. Águas doces no Brasil. São Paulo: Ed. Escrituras, 1999. Cap.3, p.75-115.

TARIFA, J.R. Fluxos polares e as chuvas de primavera-verão no Estado de São Paulo: uma análise quantitativa do processo genético. 1975. 93p. Tese (Doutorado) - Universidade de São Paulo, São Paulo.

UNAL, Y.; KINDAP, T.; KARACA, M. Redefining the climate zones of Turkey using cluster analysis. International Journal of Climatology, v.23, p.1045-1055, 2003.

UVO, B.C. Analysis and regionalization of the Northern European winter precipitation based on its relationship with the North Atlantic oscillation. International Journal of Climatology, v.23, p.11851194, 2003.

VIANELLO, R.L.; ALVES, R. Meteorologia básica e aplicações. Viçosa: Universidade Federal de Viçosa, Imprensa Universitária, 1991. 449p.

WARD, J.H. Hierarchical grouping to optimize an objective function. Journal of the American Statistical Association, v.58, p.236244, 1963.

Recebido em 1ำ de setembro de 2004 e aprovado em 18 de novembro de 2004 